Original Article

\title{
Prevalence of voice disorders in the Department of Speech- Language Pathology of a tertiary care hospital of Mangaluru: A retrospective study of 11 years
}

\author{
Thejaswi Dodderi ${ }^{1}$, Nikita Elsa Philip ${ }^{2}$, Kalpana M utum ${ }^{2}$ \\ ${ }^{1}$ Assistant Professor, ${ }^{2}$ Intern, Nitte Institute of Speech and Hearing, M angaluru.
}

Corresponding author : Thejaswi Dodderi, Assistant Professor, Nitte Institute of Speech and Hearing, Medical Sciences Complex, Nithyanandanagar, M angalore-575018. M obile : +918147461160, E-mail : thejaswi07@ gmail.com

$\begin{array}{ll}\text { Received } & : 18.01 .2018 \\ \text { Review Completed } & : 13.04 .2018 \\ \text { Accepted } & : 12.07 .2018\end{array}$

Keywords : Aphonia, dysphonia, vocal folds, voice, Dakshina Kannada

\begin{tabular}{|c|}
\hline Access this article online \\
\hline Quick Response Code \\
\hline \\
\end{tabular}

\begin{abstract}
Background: Voice disorder is now considered a 'public health concern'. Epidemiological studies of yesteryears performed in the West disseminate the importance of prevention and early identification of the change in voice. In India 'Vocology' or study of voice production is slowly emerging with specific attention to vocal health and voice care. Aim of the study: The present study implemented a retrospective observational design to identify prevalence of voice disorders in a tertiary care hospital.
\end{abstract}

M ethod: The Diagnostic register of Department of Audiology and Speech-Language Pathology of a semi-urban hospital was accessed from January 1st 2007 till January 31st 2018. Patients diagnosed with a voice disorder, in-isolation and/or in conjunction to a medical condition, were tabulated. The data was tallied under the following categories: type of voice disorder; nature of voice disorder; age of onset; gender and perceptual features.

Results: Results of the study suggested $21.4 \%$ prevalence of voice disorder. In addition the study also noted maximum prevalence of vocal nodule; adult male subjects exhibited a higher rate of vocal fold pathology and increased prevalence of perceptually hoarse voice.

Conclusion: The data from the study accounts voice problems to be on higher side with vocal fold hyper-function disorder topping the chart.

\section{Introduction}

World over, voice is regarded as a personal identity and an effective communication tool. Voice production can be pictured as a governed reflexive interplay between muscular movements and aero-dynamic principles. Vocal folds have the potential of pitching wide range of pitch and/or tone, loudness and quality. Maintaining a healthy vocal lifestyle is considered to keep the vocal folds risk-free from vocal hyper-function and/or voice pathologies like vocal nodule, vocal polyps, sulcus vocalis etcetera. Yet several intrinsic and extrinsic factors damage the sensitive multi-layered vocal folds and result in aphonia (complete loss of voice) and/or dysphonia (partial loss of voice). Due to the overwhelming impact on personal, professional, and social life, voice problems are now considered as a 'public health concern'. (1) Based on site of vocal fold lesions voice pathologies are classified into: structural pathology, inflammatory condition, systemic disorders, neurological, non-laryngeal aero-digestive, psychological, trauma and/or injury, other voice disorders and undiagnosed and/or otherwise not specified. ${ }^{(2)}$

India is a country that houses $18 \%$ of world's population. ${ }^{(3)}$ A citizen's access to public health care still remains a challenge and to some extent the private sector is bringing down this lacuna. However, the root of the problem is lack of knowledge and passive attitude towards health and healthcare system, in this scenario vocal care, among citizens and this also holds true to the multifaceted aetiology of voice disorders. Till date there has been little work in voice epidemiology and minimal efforts have been taken to comprehensively profile voice disorder data. Enumerable works related to epidemiology of communication disorders have mainly focused on hearing 
impairment ${ }^{(4)}$ and intellectual disability ${ }^{(5)}$ while neglecting speech disorders - like voice pathology. Majority of the research in voice epidemiology have been compared with Western data, which are difficult to compare with Indian population because of: differences in socio-economic status, population of the state, limited accessibility to primary health care, cultural diversity, and geographical factors. ${ }^{(6)}$ This calls in for more collaborative works and data compilation to establish a voice database for pathological conditions. With this long-term vision, the present study attempts to profile prevalence of different voice disorders reporting to the Department of Speech-Language Pathology of tertiary health care hospital in the district of Dakshina Kannada.

\section{Method}

The study implemented a retrospective observational design. Compilation of different voice disorder(s) were done using the 11 years (January $1^{\text {st }} 2007$ till January $31^{\text {st }}$ 2018) backlogs and/or records available in the Department of Audiology and Speech-Language Pathology attached to a tertiary care hospital. The diagnosis of voice disorder(s) was made by the Laryngologist using video-laryngoscopy evaluation in the Department of Oto-Rhino-Laryngology and Head and Neck Surgery. Perceptual, acoustical and aerodynamic evaluation was performed by the in-house licensed Speech-Language Pathologist. Patients undergoing voice therapy were excluded from the study design.

The data was systematically tallied using a M icrosoft excel sheet and saved in .exe format. Voice disorders were tabulated into following categories: (a) type of voice disorder, e.g. vocal nodule, vocal fold paralysis, functional aphonia etcetera; (b) nature of the voice disorder - hyperfunctional or hypo-functional, and unilateral or bilateral; (c) age of onset- between 4-12 years, 13-17 years, 18-59 years, and above 60 years; (d) gender details - male or female and (e) perceptual analysis - harsh, breathy, hoarse, and any other.

\section{Results}

The results of the study suggest that amongst 4765 communication disordered population 1020 cases were manifested with vocal fold pathology and this corresponds to $21.4 \%$ prevalence rate of voice disorder. Details of each category are enumerated below.

Type of voice disorder: Maximum voice problems were associated with (or secondary to) vocal fold nodule followed by vocal fold paralysis, laryngectomy and sulcus vocalis. On the contrary, androphonia, vocal fold hypertrophy and keratosis were few of the least prevalent voice disorder (Figure 1). The study also catego rised $32 \%$ of voice disorder as collective diagnosis of non-traditionally used terminologies like: bowing of vocal folds, intubation granuloma, sluggish vocal fold movement, arytenoids over-riding, phonasthenia, contact ulcer, tracheostomy, arytenoids congestion, post-styloidectomy, mucosal irregularity, vocal fold fibrosis, allergic reaction etcetera. In addition, cases with un-confirmed diagnosis and/or query were also put under this spectrum.

Nature of voice disorder: Results of the study indicated higher prevalence of hyper-functional voice disorder in comparison to hypo-functional voice disorder (Figure 2). Vocal fold nodule, vocal fold polyp, sulcus vocalis, puberphonia, laryngitis, vocal abuse, reinke's oedema, reflux, vocal fold cyst, diplophonia, congested vocal fold, muscle tension dysphonia, spasmodic dysphonia, keratosis, pharyngitis, hypertrophy, and androphonia were classified under hyperfunctional voice disorder; and laryngectomy, vocal fold paralysis, thyroidectomy, functional voice disorder, phonatory gap, ventricular dysphonia, and presbyphonia were deemed as hypofunctional voice disorder.

\section{Distribution of voice disorder- Age and Gender:Male} patients had a higher prevalence of voice disorder than female counterparts across paediatric and geriatric classification (Figure $3 \& 4$ ). On the contrary, in adult age group female patients were most frequently affected by the voice disorders. Interestingly, the youngest age with voice disorder was a 5 years old male with vocal nodule and oldest age was 76 years. 
Perceptual evaluation of voice disorder: Compilation of the perceptual evaluation suggested hoarse voice being highly prevalent; and breathy and harsh voices were equally prevalent (Figure 5).

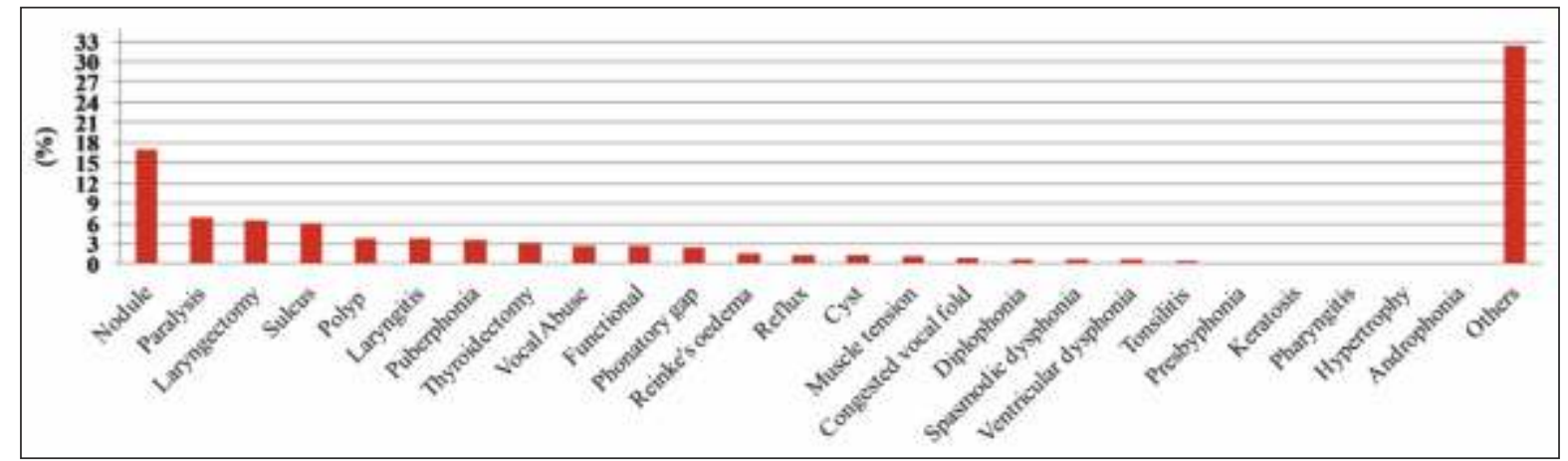

Figure 1: Disorder wise distribution of voice disorder

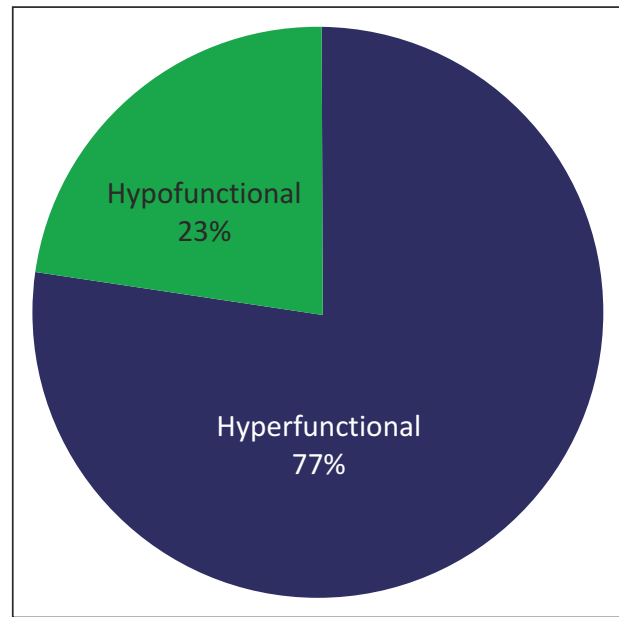

Figure $\mathbf{2}$ : Prevalence of nature of voice disorder

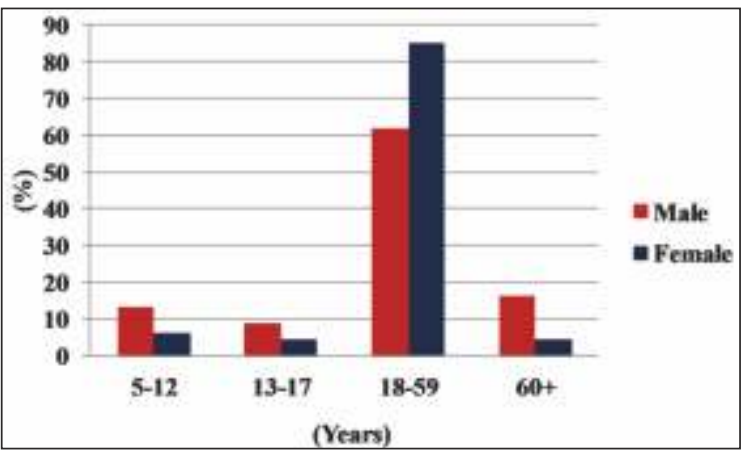

Figure 3: Age and gender wise distribution of voice disorder

\section{Discussion}

This retrospective study was undertaken to observe the prevalence rate of voice disorders in a semi-urban hospital of Mangaluru city, Dakshina Kannada district. The study systematically tallied the voice disorders from the database of the Department of Audiology and Speech-Language

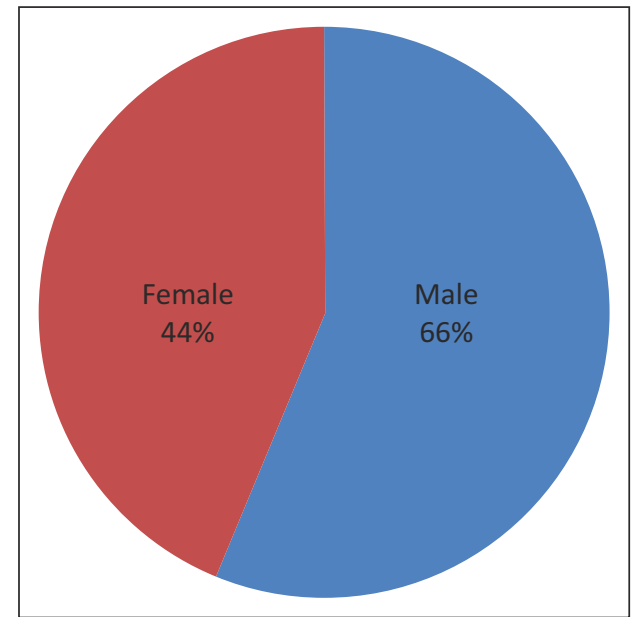

Figure 4: Gender wise distribution of voice disorder

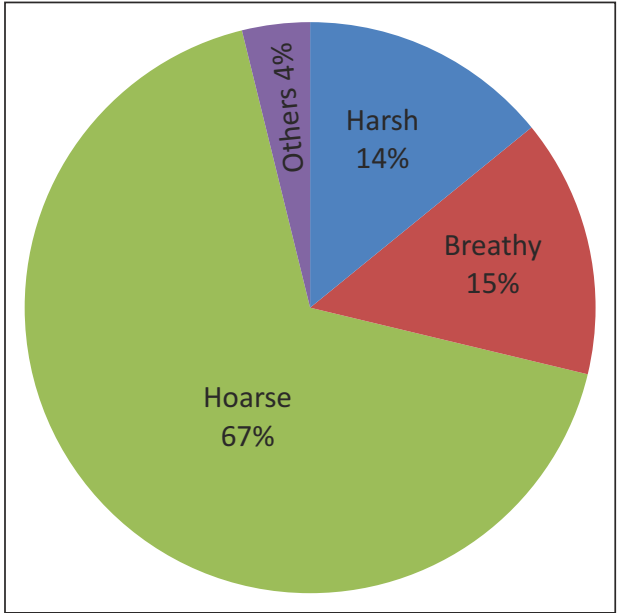

Figure 5: Distribution of perceptual features of voice disorder

Pathology using a pre-determined classification system. In the present study maximum number of hyperfunctional voice disorder cases was evidenced and this indicates poor 
vocal hygiene program and increased vocal abuse practices by the community at large. Specifically, our study reports $17.05 \%$ vocal nodule, 3.72 vocal polyps, and 6.37 laryngeal cancers and these are lower than the literature that estimates $22 \%, 19 \%$ and $17 \%$ respectively. ${ }^{(7)}$ Higher prevalence of voice disorders could be attributed to lack of correct referrals, un-availability of cutting edge diagnostic tools, limited access to professional consultation, irregular follow up programs.

In India, laryngeal cancer sums up to 3-6\% of all cancer in men and has the highest incidence rate of $8.18 / 100,000 .{ }^{(8)}$ Congruence to the literature, in the present study $6.37 \%$ laryngeal cancer patients has undergone laryngectomy. Surprisingly, India carries $17 \%$ of world cancer burden and this is expected to increase exponentially. ${ }^{(9)}$ Despite this alarming number and predicted exponential rise, regrettably, there is availability of Oncologist and/or Otorhino-laryngologist to meet the surgical demands of cancer treatment; but dearth of professional experts in voice restoration post-laryngectomy remains a challenge. Few setups like Tata Memorial Hospital, Mumbai; Kasturba M edical College, Manipal; and few healthcare institutions offer holistic care to the laryngectomee.

Collective evidences from epidemiological studies pinpoint increased voice problems in females compared to males. ${ }^{(10)}$ This observation holds true only to the adult population of the study, in which adult females had $85.04 \%$ voice disorder and adult males had $61.7 \%$ prevalence rate. Vulnerability to voice problems in female could be because of thyroid related problems. It is known that thyroid secretion hormone regulates fluid retention in the vocal folds by balancing the polysaccharides levels and this in turn prevents thickening of layers of the vocal fold. Hence, in presence of co-morbid thyroid conditions the vocal fold mucosa is altered and places the laryngeal apparatus at high risk for voice change. Increased risk of thyroid problems is often reported in females (15.86\%) than males (5.02\%); and in India thyroid problems have an estimate of
$11 \%{ }^{(11,12)}$ Studies also reports in severe form of hyperthyroidism one can present with hoarseness of voice. ${ }^{(13)}$ On the contrary, in children and geriatrics, male patients had increased voice problems and this could be due to increased vocal abuse and gender stereotype that puts higher vocal demand in males. The result of the present study also highlights the increase in peripheral nerve assaults, specifically recurrent branch of the vagus nerve, resulting in vocal fold paralysis. ${ }^{(14)}$

\section{Conclusion}

The present study implemented a retrospective design to profile the voice disorder reporting to a tertiary care hospital. The outcome of the study was that voice disorders are on a rampant and vocal nodule is the most commonly occurring vocal fold pathology. Collectively, higher prevalence of hyper-adduction voice disorder shed light on poor vocal health care. The practical exercise of this study is far-reaching and the public at large are its beneficiaries. Majority of the voice pathologies are preventable and this study must enable us to strive more professionally by means of promoting public awareness, disseminate manpower and resources to increase the availability of professional services. This study also serves as a roadmap for prevention policies with immediate emphasis of preventing vocal hyper-function disorders. Further studies must cauldron data from multi-centric centres and estimate not just point-prevalence but obtain information on treatment-seeking and non-treatment seeking population and their follow up.

\section{Acknowledgement}

The author(s) extend their gratitude to the Director, Nitte Institute of Speech and Hearing for permitting us to carry out this research. We also thank the Principal, Nitte Institute of Speech and Hearing for her constant support. We sincerely express our profound thank you to the entire faculty at the Department of Othorhinolaryngology, Justice K S Hedge Hospital, Mangaluru for their un-conditional help. 


\section{References}

1. Boominathan P. Expanding Frontiers in Voice Health \& CareApplications for India. J All India Inst Speech \& Hear 2016; 35: 9-13.

2. Verdolini K, Rosen CA, Branski RC. Classification Manual for Voice Disorders- I. 2014; Lawrence Erlbaum Associates, London.

3. United Nations Department of Economics and Affair Division. Retrieved on 12 January 2018 from http://www.un.org/en/ development/desa/publications/world-population-prospects-2015revision.html

4. Garg S, Chadha S, Malhotra S, Agarwal A. Deafness: Burden, Prevention and Control in India. Natl M ed J India 2009; 22: 79-81.

5. Kumar SG, Das A, Bhandary PV, Soans SJ, Kumar HNH, Kotian MS. Prevalence and pattern of mental disability using Indian disability evaluation assessment scale in a rural community of Karnataka. Indian J Psychiatry 2008;50:21-23.

6. Sreeraj K, Suma C, Jayarama G, Sandeep M, M ahima G, Shreyank PS. Prevalence of communication disorders in a rural population of Republic of India. J Hear Sci 2013; 3: 41-49.

7. Rameshkumar E, Rosmi TK. Prevalence of age, gender and pathological conditions of vocal cordsleading to hoarseness of voice in a tertiary care hospital. Int J Adv M ed 2017; 3: 345-348.

8. Obdey S, Jain A, Balasubramanium G. Epidemiological review of laryngeal cancer: An Indian perspective. Indian J M ed Paediatr Oncol 2015; 36: 154-160

9. Sankaranarayanan R, Ramanakumar AV, Yeole BB. Survival from glottic and supraglottic laryngeal carcinoma in M umbai (Bombay), India. Oral Oncol 2003; 39: 656-663.

10. Roy N, M errill RM, Thibeault SL, et al. Prevalence of voice problems in teachers and the general population. J Speech Lang Hear Res 2004; 47:281-293.

11. Unnikrishnan AG, Kalra S, Sahay RK, Bantwal G, John M, Tewari N. Prevalence of hypothyroidism in adults: An epidemiological study in eight cities of India. Indian J Endocr M etab 2013; 17: 647-652.

12. Bagcchi S. Hypothyroidism in India: more to be done. Lancet- Diabetes Endocrinol 2014; 2: 778-778.

13. Kadakia S, Carison D, Sataloff R. The effects of hormones on the voice. J Sing 2013; 69:571-574.

14. Linville SE. Vocal Aging. 2001; Singular Thomson Learning, San Diego. 